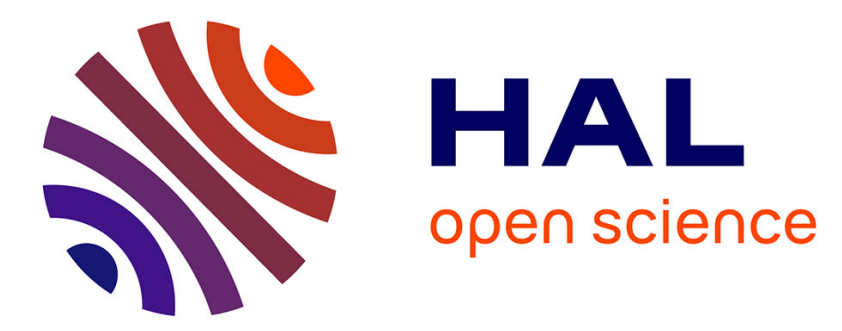

\title{
$\beta$-Cyclodextrins grafted with chiral amino acids: A promising supramolecular stabilizer of nanoparticles for asymmetric hydrogenation?
}

Nguyet Trang Thanh Chau, Jean-Paul Guégan, Stephane Menuel, Miguel Guerrero, Frédéric Hapiot, Eric Monflier, Karine Philippot, Audrey

Denicourt-Nowicki, Alain Roucoux

\section{To cite this version:}

Nguyet Trang Thanh Chau, Jean-Paul Guégan, Stephane Menuel, Miguel Guerrero, Frédéric Hapiot, et al.. $\beta$-Cyclodextrins grafted with chiral amino acids: A promising supramolecular stabilizer of nanoparticles for asymmetric hydrogenation?. Applied Catalysis A : General, 2013, 467, pp.497-503. 10.1016/j.apcata.2013.08.011 . hal-00860860

\section{HAL Id: hal-00860860 https://hal.science/hal-00860860}

Submitted on 11 Sep 2013

HAL is a multi-disciplinary open access archive for the deposit and dissemination of scientific research documents, whether they are published or not. The documents may come from teaching and research institutions in France or abroad, or from public or private research centers.
L'archive ouverte pluridisciplinaire HAL, est destinée au dépôt et à la diffusion de documents scientifiques de niveau recherche, publiés ou non, émanant des établissements d'enseignement et de recherche français ou étrangers, des laboratoires publics ou privés. 


\title{
$\beta$-Cyclodextrins grafted with chiral amino acids: a promising supramolecular stabilizer of nanoparticles for asymmetric hydrogenation ?
}

\author{
Nguyet Trang Thanh Chau, ${ }^{\text {a,b }}$ Jean-Paul Guégan, ${ }^{\text {a,b }}$ Stéphane Menuel, ${ }^{\mathrm{c}}$ Miguel Guerrero, d,e \\ Frédéric Hapiot, ${ }^{\mathrm{c}}$ Eric Monflier, ${ }^{\mathrm{c}}$ Karine Philippot, ${ }^{\mathrm{d}, \mathrm{e}}$ Audrey Denicourt-Nowicki, ${ }^{\mathrm{a}, \mathrm{b}, *}$ and \\ Alain Roucoux ${ }^{\mathrm{a}, \mathrm{b}, *}$ \\ ${ }^{a}$ Ecole Nationale Supérieure de Chimie de Rennes, CNRS UMR 6226, 11, allée de Beaulieu, \\ CS 50837, 35708 Rennes cedex 7, France. \\ Fax: (+33) 022323 8199; Tel: (+33) 0223238037. \\ E-mail: alain.roucoux@ensc-rennes.fr \\ ${ }^{\mathrm{b}}$ Université Européenne de Bretagne \\ ${ }^{\mathrm{c}}$ Université d'Artois, CNRS UMR 8181, Faculté des Sciences Jean Perrin, Rue Jean Souvraz, \\ SP 18, F-62307 Lens Cedex, France. \\ ${ }^{\mathrm{d}}$ CNRS; LCC (Laboratoire de Chimie de Coordination), 205 Route de Narbonne, F-31077 \\ Toulouse, France. \\ ${ }^{\mathrm{e}}$ Université de Toulouse; UPS, INPT, LCC, F-31077 Toulouse, France
}

\begin{abstract}
Water-soluble ruthenium nanoparticles stabilized by randomly methylated $\beta$-cyclodextrins (RaMeCDs) grafted with chiral amino-acid moieties like L-alanine (Ala) and L-leucine (Leu) were prepared in aqueous solution by two approaches: i) a one-step hydrogen reduction of ruthenium trichloride as metal source in the presence of appropriate cyclodextrins (one-pot method) or ii) a $\mathrm{NaBH}_{4}$ reduction of the metal salts, followed by the stabilization of ruthenium hydrosol by the addition of chirally modified RaMeCDs (cascade method). The influence of the ligand's nature and the synthesis methodologies on the size, dispersion and surface properties of the obtained ruthenium colloids were studied by TEM and NMR analyses. The spherical ruthenium suspensions contain very small particles $(0.82-1.00 \mathrm{~nm})$ with narrow size distributions. Their catalytic properties were evaluated in biphasic hydrogenation of various prochiral compounds (olefins, ketones and disubstituted arenes) showing promising results in terms of activity and selectivity. Nevertheless, no significant enantiomeric excesses were observed.
\end{abstract}

Key Words: Ruthenium nanoparticles - Aqueous suspension - grafted cyclodextrins - biphasic catalysis

\section{Introduction}

Optically active cyclohexyl moieties play a key role in the synthesis of various biologically active molecules or auxiliaries.[1] Among the various strategies, enzymatic or chemical resolution approaches[2] or chiral auxiliarybound substrates[3-6] were used to produce these optically enriched intermediates. An elegant alternative method will rely on the catalytic diastereoselective hydrogenation of monocyclic polysubstituted benzenes. Recently, metal nanoparticles (NPs) have emerged as a pertinent class of catalysts for various reactions, [7, 8] and especially for arene hydrogenation under mild conditions, $[9,10]$ owing to their original surface reactivities.[11-13] Their preparation usually requires the presence of protective agents such as surfactants, polymers, or ligands, etc.[14-16] Towards the increasing demand in optically enriched intermediates, various chiral compounds have been investigated as protective agents of colloidal species for the development of asymmetric catalytic reactions. In this case, the coating agents should be able to transmit their chiral information to the substrate and thus control the enantiodiscrimination in reduction processes. $[17,18]$ According to our knowledge, only a few chirally modified metal nanocatalysts have been described in the hydrogenation of prochiral aromatic molecules within organic media.[10] First studies were performed in the hydrogenation of $o$ cresol derivatives using colloidal rhodium protected by a chiral lipophilic amine $(R)$-(-)-dioctylcyclohexyl-1ethylamine (DOCEA), leading to very low asymmetric induction.[19] Metal NPs stabilized by chiral N-donor ligands[20] or carbohydrate derived 1,3-diphosphite ligands[21, 22] also revealed poor enantiomeric excess (ee) values in the hydrogenation of methylanisole isomers.

Besides, in order to fit in with green chemistry principles,[23] the use of finely dispersed nanoparticles in water, a readily available and environmentally benign solvent, has gained growing attention due to their recovery ability and easy work-up.[24-28] In this aqueous medium, the problematic undissolved substrates can be 
circumvented by the use of micellar systems,[29, 30] like surfactants.[31-34] In this context, our group has described a series of optically amphiphilic compounds, derived from $N$-methylephedrine, $N$-methylprolinol or cinchona derivatives possessing various counter-ions as efficient stabilizers of rhodium NPs in water.[35], [36] These nanocatalysts proved to be highly active in the asymmetric hydrogenation of ethyl pyruvate or prochiral disubstituted benzenes, with modest enantiodiscrimination.

An alternative approach to improve biphasic catalytic processes consists on the use of inverse phase-transfer catalysts, such as cyclodextrins (CDs) or calixarenes.[37-39] In case of CDs, physico-chemical properties could be easily modulated through the choice of the cavity's size, the nature of the substituents and the substitution degree.[40], [41] Among them, randomly methylated $\beta$-cyclodextrins (RaMeCD) have proved to be particularly efficient [37, 42, 43] and have demonstrated to be promising candidates as stabilizers for metallic nanospecies in water.[44] Based on these physic-chemical properties, our group has investigated RaMeCD-protected ruthenium NPs $\left(\mathrm{Ru}^{0} \mathrm{NPs}\right)$ as nanocatalysts in the hydrogenation of olefins,[45] ketones[46] and arenes.[45, 47] Recently, the influence of the preparation method on NPs size as well as on their reactivity has particularly been studied.[46] Both synthesis methodologies (one-pot and cascade) led to very small NPs with narrow size distributions, which proved to be very active in the reduction of model substrates.

Although the use of CDs-based structures in chiral discrimination is well-documented,[48] the use of CDs modified by chiral substituents for the stabilization of NPs and their application in enantioselective hydrogenations has not been described to our knowledge. Here, we report the synthesis of novel ruthenium NPs capped by methylated CDs grafted with chiral moieties, such as L-alanine (RaMeCD-trz-Ala) or L-leucine (RaMeCD-trz-Leu) (Fig. 1) in order to induce asymmetry during supramolecular recognition processes. These supramolecules[49] were synthesized in 5 steps from mono-6-azido RaMeCD precursor using click synthesis[50] with good yields and were subsequently used to avoid aggregation of $\mathrm{Ru}^{0} \mathrm{NPs}$ during their preparation. Two easy and reproducible routes (one-pot and cascade methods) were applied for the synthesis of $\mathrm{Ru}^{0}$ colloids and their comparison. Their characterizations have been performed by Transmission Electron Microscopy (TEM) and Diffusion Ordered SpectroscopY (DOSY) experiments while their catalytic reactivity was compared in the biphasic asymmetric hydrogenation of various prochiral substrates. In a first set of experiments, methyl 2-acetamidoacrylate and ethyl pyruvate were studied as model substrates of a prochiral functionalized olefin and ketone, respectively. Acetophenone was also investigated as a pertinent substrate in terms of chemoselectivity (carbonyl group vs. aromatic ring) and stereoselectivity through the asymmetric reduction of the ketone function. Finally, the obtained nanocatalysts were evaluated in the stereoselective reduction of a prochiral arene ( $m$-methylanisole), which remains a real challenge in asymmetric catalysis field.

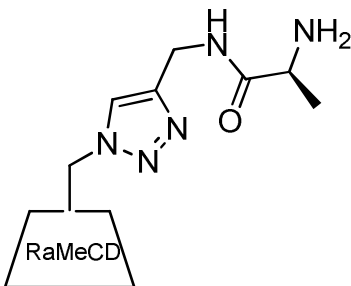

RaMeCD-trz-Ala

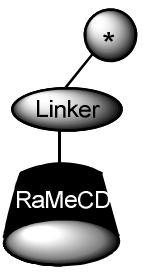

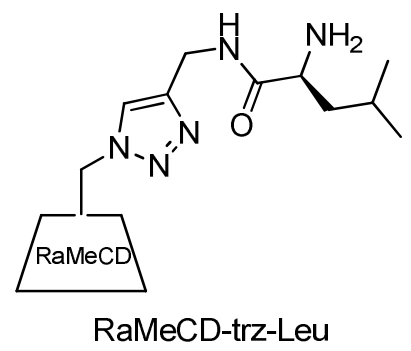

Fig. 1. Structure of grafted $\beta$-cyclodextrins with chiral amino-acid moieties like L-alanine (Ala) and L-leucine (Leu)

\section{Experimental}

\subsection{Reagents and chemicals}

Randomly methylated $\beta$-cyclodextrin (RaMeCD (1.8)) was purchased from Sigma-Aldrich. This cyclodextrin was partially methylated. Methylation occurred at positions C2, C3 or C6 and $1.8 \mathrm{OH}$ groups per glucopyranose unit were statistically modified. L-Alanine- $N$-[(1-randomly methylated- $\beta$-cyclodextrinyl- $1 H-1,2,3$-triazol-4yl)methyl amide] (RaMeCD-trz-Ala) and L-leucine- $N$-[(1-randomly methylated- $\beta$-cyclodextrinyl- $1 H$ - $1,2,3$ triazol-4-yl)methylamide] (RaMeCD-trz-Leu) were prepared according to a previously described procedure.[49] Ruthenium chloride hydrate was obtained from Strem Chemicals. Sodium borohydride and all substrates were purchased from Sigma-Alrich, Acrōs Organics or Alfa Aesar and were used without further purification. Water was purified using Millipore Elix 5 (type MSP 100) system.

\subsection{Analytical procedures}

\subsubsection{TEM analysis}

Transmission electron microscopy (TEM) images were performed at "Service Commun de Microscopie Electronique de l'Université Paul Sabatier" (UPS-TEMSCAN) in Toulouse or at "Université Pierre et Marie 
Curie". They were recorded with a JEOL 1011 electron microscope operating at $100 \mathrm{kV}$ with resolution point of $4.5 \AA$ or with a JEOL TEM 100CXII electron microscope operated at an acceleration voltage of $100 \mathrm{kV}$, respectively. A drop of $\mathrm{Ru}^{0}$-NPs in water was deposited on a carbon-coated copper grid and dried in air. The size distributions were determined through a manual analysis of enlarged micrographs with Image $\mathbf{J}$ software using Microsoft Excel to generate histograms of the statistical size distribution and a mean diameter. At least 200 particles on a given grid were measured in order to obtain a statistical size distribution and a mean diameter.

\subsubsection{NMR analysis}

DOSY NMR was recorded on a Bruker Avance III 400 spectrometer at $400.13 \mathrm{MHz}$ for ${ }^{1} \mathrm{H}$ and equipped with a BBFO probe and Z-gradient coil and a GREAT 1/10 gradient unit. All experiments were recorded using the 2DPGSE sequence for diffusion measurement using stimulated echo with bipolar gradient without spinning. The relaxation delay was adjusted to $3 \mathrm{~s}$ while the big DELTA and the little DELTA were set at $50 \mathrm{~ms}$ and $3200 \mu \mathrm{s}$, respectively. A series of 16 experiments of 64 or 80 scans was recorded. The shape of the gradient was rectangular and its duration was $5 \mathrm{~ms}$. The strength of the gradient was varied during the experiments and calibrated by measuring the self-diffusion of the residual HDO signal at $298 \mathrm{~K}$ of a doped water tube containing $1 \% \mathrm{H}_{2} \mathrm{O}$ in $\mathrm{D}_{2} \mathrm{O}$, with $0.1 \mathrm{mg} \mathrm{GdCl} / \mathrm{mL} \mathrm{D}_{2} \mathrm{O}$ and $0.1 \% \mathrm{CH}_{3} \mathrm{OH}\left(1.87 \times 10^{-9} \mathrm{~m}^{2} . \mathrm{s}^{-1}\right)$. All the spectra were acquired using $65 \mathrm{~K}$ points and $5600 \mathrm{~Hz}$ and processed with the Bruker Topspin software package DOSY using a line broadening of $1 \mathrm{~Hz}$. All of samples (RaMeCD-trz-Ala, mixture of $\mathrm{RuCl}_{3} \cdot 3 \mathrm{H}_{2} \mathrm{O}$ and RaMeCD-trz-Ala or $\mathrm{Ru}^{0} @ \mathrm{RaMeCD}$-trz-Ala NPs synthesised by one-pot method) were prepared in $\mathrm{D}_{2} \mathrm{O}$ solution at a concentration of 7.2 mM of RaMeCD-trz-Ala and analysed at 298K.

\subsubsection{Gas chromatography}

For hydrogenation of prochiral substrates, the conversion and the enantiomeric excess were determined by gas chromatography using Fisons Instruments GC 9000 series with FID detector equipped with a chiral Varian Chiralsil-Dex CB capillary column $(30 \mathrm{~m}, 0.25 \mathrm{~mm}$ i.d.). Parameters were as follows: isotherm program with oven temperature, $90{ }^{\circ} \mathrm{C}$ (ethyl pyruvate and $m$-methylanisole) or $130{ }^{\circ} \mathrm{C}$ (acetophenone and methyl 2acetamidoacrylate); carrier gas pressure, $50 \mathrm{kPa}$.

\subsection{Synthesis of aqueous ruthenium(0) suspension}

\subsubsection{One-pot method}

To an aqueous solution $(6 \mathrm{~mL})$ of $\mathrm{RuCl}_{3} 3 \mathrm{H}_{2} \mathrm{O}\left(3.8 \mathrm{mg}, 1.44 \times 10^{-2} \mathrm{mmol}\right)$ was added at once cyclodextrin (RaMeCD-trz-Ala or RaMeCD-trz-Leu) $\left(7.2 \times 10^{-2} \mathrm{mmol}\right)$ dissolved in $4 \mathrm{~mL}$ of water. The mixture was vigorously stirred at room temperature under $\mathrm{H}_{2}$ atmosphere $\left(\mathrm{P}_{\mathrm{H} 2}=1\right.$ bar) until the reaction's colour turned from dark brown to green brown (about 5-7 h). The colloidal ruthenium solution was then stirred overnight at room temperature before used in catalytic test.

\subsubsection{Cascade method}

To an aqueous solution $(50 \mathrm{~mL})$ of $\mathrm{RuCl}_{3} 3 \mathrm{H}_{2} \mathrm{O}(26.1 \mathrm{mg}, 0.1 \mathrm{mmol})$ was added dropwise and under vigorous stirring a freshly prepared aqueous solution (about $1.8 \mathrm{~mL}$ ) of $\mathrm{NaBH}_{4} 0.1 \mathrm{M}$ at room temperature. The reduction occurred quickly and was characterized by a progressive colour change from dark brown to light brown then green brown. The addition of $\mathrm{NaBH}_{4}$ was stopped when an additional drop made all of reaction solution turn dark brown while the $\mathrm{pH}$ value was kept lower 4.9. The colloidal solution was then stirred overnight at room temperature before addition of the aqueous solution $(48.2 \mathrm{~mL}$ ) of cyclodextrin (RaMeCD-trz-Ala or RaMeCDtrz-Leu) $(0.5 \mathrm{mmol})$. The obtained ruthenium nanoparticles were stirred for $24 \mathrm{~h}$ before used in catalytic test.

\subsection{General procedure for high pressure hydrogenation reactions}

The stainless steel autoclave was charged with the aqueous colloidal ruthenium suspension $(10 \mathrm{~mL}$, $1.44 \times 10^{-2} \mathrm{mmol}$ or $1.00 \times 10^{-2} \mathrm{mmol}$ for the catalyst prepared by one-pot or cascade methods, respectively) and appropriate substrate $\left([\right.$ substrate $] /\left[\mathrm{Ru}^{0}\right]$ ratio $\left.=100 / 1\right)$. The autoclave was degassed three times and hydrogen gas was admitted to the system at a constant pressure $(20$ bars). The mixture was stirred vigorously at room temperature for time (h). Samples were removed from time to time to monitor the reaction by gas chromatography in previously mentioned conditions.

\subsection{General procedure for catalytic lifetime tests}

The stainless steel autoclave was charged with the aqueous colloidal ruthenium suspension (10 $\mathrm{mL}$, $1.44 \times 10^{-2} \mathrm{mmol}$ or $1.00 \times 10^{-2} \mathrm{mmol}$ for the NPs produced by the one-pot or cascade methods, respectively) and ethyl pyruvate $\left([\right.$ substrate $] /\left[\mathrm{Ru}^{0}\right]$ ratio $\left.=100 / 1\right)$. The autoclave was degassed three times and hydrogen gas was admitted to the system at a constant pressure $\left(20\right.$ bar $\left.\mathrm{H}_{2}\right)$. The mixture was stirred vigorously at room temperature until total conversion of ethyl pyruvate $(18 \mathrm{~h}$ and $6 \mathrm{~h}$ depending on the catalyst system). The aqueous phase was washed successively with EtOAc $(4 \times 10 \mathrm{~mL})$ then stirred overnight before reuse in the next run. 


\section{Results and discussion}

\subsection{Synthesis of ruthenium( $(0)$ nanoparticles}

Based on results previously obtained in our group with $\mathrm{Ru}^{0} @ \mathrm{RaMeCD}$ systems,[46] ruthenium nanoparticles were prepared through two approaches, one-pot $\left(\mathrm{H}_{2}\right.$ gas reduction) and cascade $\left(\mathrm{NaBH}_{4}\right.$ chemical reduction) routes (Scheme 1).

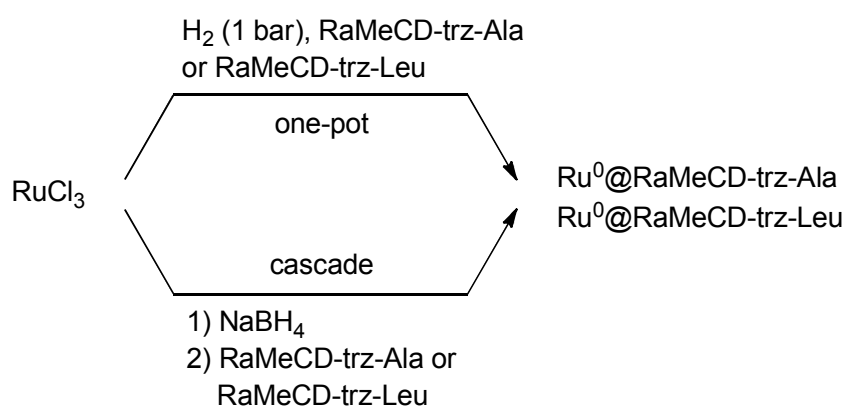

Scheme 1. Two methodologies for Ru0@RaMeCD-trz-Ala and Ru0@RaMeCD-trz-Leu NPs synthesis

In the one-pot method, ruthenium(III) chloride was simultaneously reduced under hydrogen pressure at room temperature (rt) and stabilized in water in the presence of appropriate chiral cyclodextrins (RaMeCD-trz-Ala or $\mathrm{RaMeCD}-\mathrm{trz}-\mathrm{Leu}$ ) (5 eq). The higher steric hindrance of grafted CDs and/or the coordination of the metal precursor with triazole moieties[51,52] rendered the reduction more difficult than previously observed for the preparation of $\mathrm{Ru}^{0} @ \mathrm{RaMeCD} \mathrm{NPs}$, thus requiring a longer reaction time.

The cascade method consists on the preparation of $\mathrm{Ru}^{0}$ suspensions in two steps: i) chemical reduction of $\mathrm{RuCl}_{3}, 3 \mathrm{H}_{2} \mathrm{O}$ by a dropwise addition of an aqueous $\mathrm{NaBH}_{4}$ solution;[53] ii) post-stabilization of obtained $\mathrm{Ru}^{0}$ hydrosol by addition of 5 eq of suitable chiral CDs. Therefore, this strategy offers a great advantage, allowing the modulation of the cyclodextrin's amount.

\subsection{Characterisation of ruthenium $(0)$ nanoparticles}

The water-soluble Ru@ ${ }^{0}$ RaMeCD-trz-Ala or Ru ${ }^{0} @$ RaMeCD-trz-Leu colloids obtained by both methods were characterized by TEM analysis,[54] in order to correlate the influence of the ligands and the preparation approaches on the size, morphology and dispersion of the metallic cores of the NPs. The micrographs and the size distributions are presented in Fig.2 and Fig. 3.
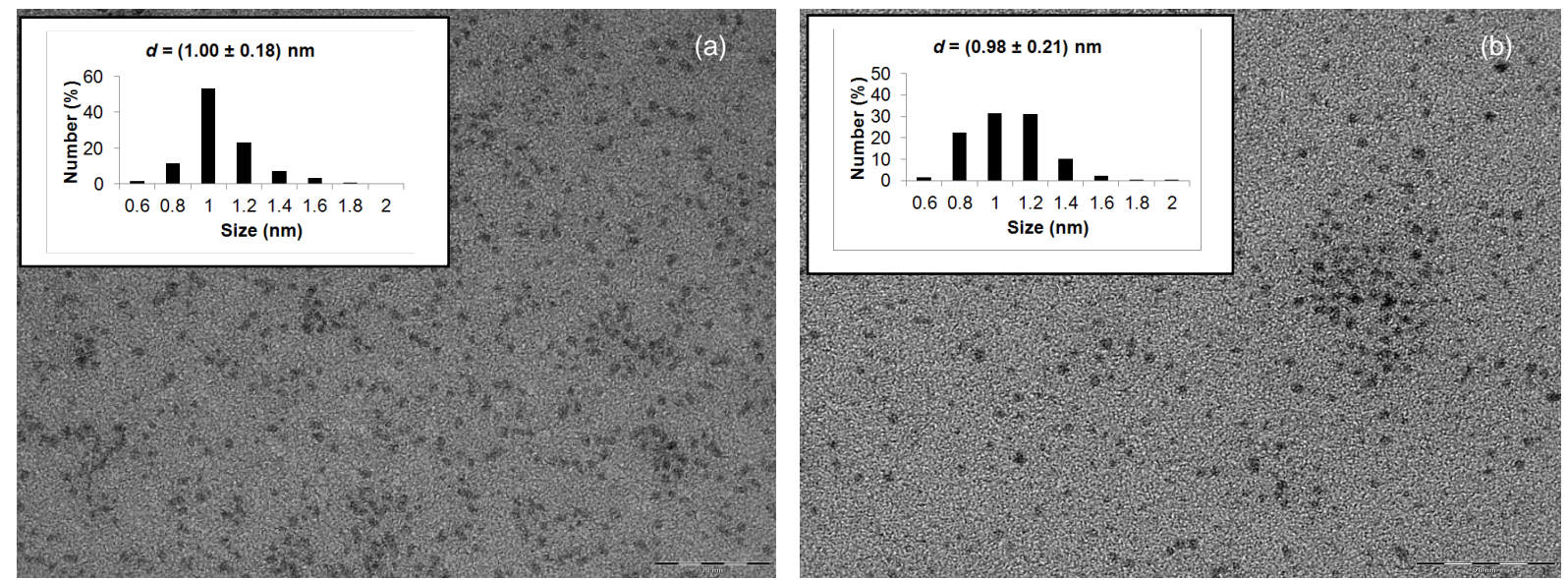

Fig. 2. TEM images of $\mathrm{Ru}^{0} @ \mathrm{RaMeCD}$-trz-Ala NPs prepared by (a) one-pot method (Scale bar = 20nm) and (b) cascade method $($ Scale $\mathrm{Bar}=20 \mathrm{~nm})$

In all cases, the colloids were well-dispersed on the grid, with spherical morphologies and narrow standard deviations. The $\mathrm{Ru}^{0} \mathrm{NPs}$ displayed a mean size in the range $0.82-1.00 \mathrm{~nm}$, depending on the ligand nature and the preparation methods. The more sterically hindered ligand, L-leucine-grafted cyclodextrin, appeared to be more effective than its alanine analogue in the stabilization of $\mathrm{Ru}^{0}$ suspensions, leading to the formation of 
smaller NPs (0.96 and $0.82 \mathrm{~nm}$ vs. 1.00 and $0.98 \mathrm{~nm}$, respectively). In addition, while similar sizes were observed with RaMeCD-trz-Ala-protected $\mathrm{Ru}^{0}$ NPs synthesized by both approaches (Fig. 2), the $\mathrm{Ru}^{0} \mathrm{NPs}^{\circ}$ prepared by the cascade strategy were slightly smaller than those obtained by the one-pot method in the case of RaMeCD-trz-Leu as stabilizing agent (Fig. 3a vs. Fig 3b). This better control of the NPs growth could result from the pre-stabilization of $\mathrm{Ru}^{0}$ hydrosol with hydronium ions or other hydrated ions $\left(\mathrm{H}_{5} \mathrm{O}_{2}{ }^{+}, \mathrm{H}_{7} \mathrm{O}_{3}{ }^{+}\right.$, etc.) generated during the $\mathrm{NaBH}_{4}$ reduction of the $\mathrm{RuCl}_{3} \cdot 3 \mathrm{H}_{2} \mathrm{O}$.[53] Moreover, in comparison with $\mathrm{Ru}^{0} @ \mathrm{RaMeCD}$ systems, [46] these NPs exhibited smaller diameters. As previously mentioned, [53, 54] this phenomenon could be explained by the protonation of Ala or Leu moieties at $\mathrm{pH}$ of medium ( 4.9), thus producing ammonium forms that may reinforce the NPs stability within aqueous solution thanks to coulombic interactions[55, 56] while the RaMeCD backbone provides only a steric stabilization.

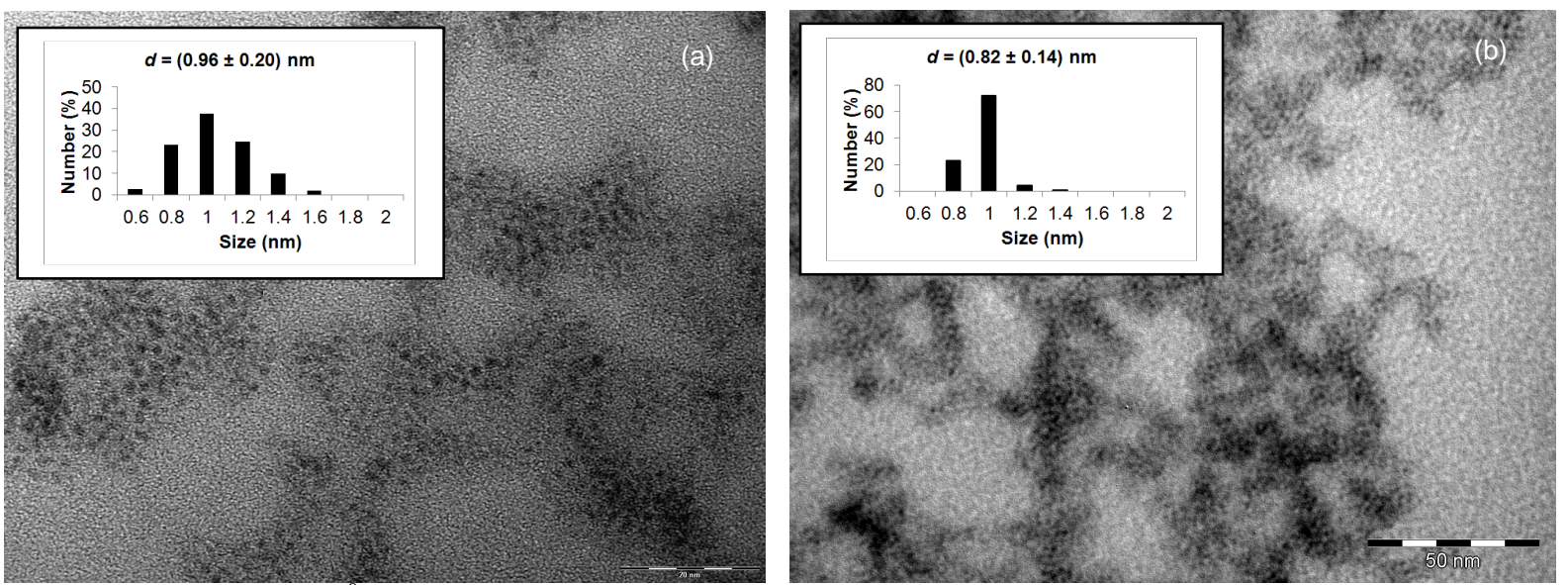

Fig. 3. TEM images of Ru@ RaMeCD-trz-Leu NPs prepared by (a) one-pot method (Scale bar = $20 \mathrm{~nm}$ ) and (b) cascade method $($ Scale bar $=50 \mathrm{~nm})$

As comparable size and morphology of NPs were observed, Ru $u^{0}$ RaMeCD-trz-Ala produced from the one-pot method was chosen among these nanocatalysts for NMR investigation in order to study the nature of the interactions between the protective agent and the metallic core. ${ }^{1} \mathrm{H}$ NMR measurements in $\mathrm{D}_{2} \mathrm{O}$ solution of the $\mathrm{CDs}$ and the corresponding $\mathrm{Ru}^{0} \mathrm{NPs}$ showed no significant difference in the chemical shifts of the chirally modified CDs. Moreover, DOSY analysis[57] indicated quite similar values of diffusion coefficient $(D)$ of these samples at the given concentration $(7.2 \mathrm{mM}$ ) (Table 1, Entries 1 and 2). These results evidenced the very weak interactions between the CDs and the metallic core in opposition to the coordination induced by strong ligands, such as 1,3,5-triaza-7-phosphaadamantane (PTA).[58]

Table 1. $D$ values and $\mathbf{r}_{H}$ values determined by DOSY NMR

\begin{tabular}{cccc}
\hline Entry & Sample & $\boldsymbol{D}\left(\mathbf{1 0}^{-\mathbf{1 0}} \mathbf{~ m}^{\mathbf{2}} \cdot \mathbf{s}^{\mathbf{- 1}}\right)$ & $\mathbf{r}_{\mathbf{H}}(\mathbf{n m})$ \\
\hline 1 & RaMeCD-trz-Ala & 2.267 & 0.851 \\
2 & $\mathrm{Ru}^{0} @$ RaMeCD-trz-Ala & 2.290 & 0.842 \\
3 & $\mathrm{RaMeCD}[46]$ & 2.460 & 0.784 \\
4 & $\mathrm{Ru}^{0} @$ RaMeCD [46] & 2.463 & 0.783 \\
\hline
\end{tabular}

${ }^{\mathrm{a}} \mathrm{NMR}$ analysis performed at $298 \mathrm{~K}$ in $\mathrm{D}_{2} \mathrm{O} .{ }^{\mathrm{b}} \mathrm{NPs}$ were prepared by one-pot method.

Compared to $\mathrm{Ru}^{0} @$ RaMeCD NPs, chirally modified CDs-stabilized Ru $\mathrm{Ru}^{0}$ colloids displayed comparable $D$ values $\left(2.463 \times 10^{-10}\right.$ and $2.290 \times 10^{-10} \mathrm{~m}^{2} \cdot \mathrm{s}^{-1}$, respectively) (Table 1, Entries 4 and 2). This slightly slower diffusion in $\mathrm{D}_{2} \mathrm{O}$ solution could be attributed to the higher steric hindrance and the potential electrostatic stabilization of the RaMeCD-trz-Ala. The hydrodynamic radius $r_{H}[59]$ of these self-diffusing species were calculated from $D$ using the Stokes-Einstein equation. These values revealed that the aggregation state of CDs near the particle is very low. Finally, these DOSY NMR experiments suggest the presence of non-aggregated but mobile CDs acting as a dispersive agent around the particle surface.

\subsection{Biphasic catalytic hydrogenation of prochiral substrates using ruthenium(0) nanoparticles}

The Ru0@RaMeCD-trz-Ala and Ru@ @RaMeCD-trz-Leu NPs have been investigated in the reduction of various prochiral substrates, such as an activated olefin (methyl 2-acetamidoacrylate), a linear ketone (ethyl pyruvate), an aromatic ketone (acetophenone) and a disubstituted arene ( $m$-methylanisole). The hydrogenation of these model compounds was carried out under biphasic conditions (water/substrate) at room temperature and monitored by gas chromatography analysis. In addition, these reactions have been performed at 20 bar $\mathrm{H}_{2}$ since 
no conversion was observed at atmospheric hydrogen conditions as shown in previous studies.[46, 60] Moreover, the stability of the triazole ring under reduction conditions of the synthesis and the catalysis was also demonstrated.[51, 52,61] The catalytic performances of these systems are reported in Table 2 and Table 3.

Table 2. Hydrogenation of methyl 2-acetamidoacrylate and ethyl pyruvate using Ru'@ RaMeCD-trz-Ala and Ru'0 RaMeCD-trz-Leu ${ }^{\mathrm{a}}$

\begin{tabular}{ccccccc}
\hline Entry & Substrate & Chiral moiety & Method & t (h) & Products & $\begin{array}{c}\text { Yields } \\
(\boldsymbol{\%})^{\mathbf{b}}\end{array}$ \\
\hline 1 & & Ala & One-pot & 6 & & 100 \\
2 & Methyl 2- & Leu & One-pot & 6 & Methyl 2-acetamidopropanoate & 100 \\
3 & acetamidoacrylate & Ala & Cascade & 6 & & 100 \\
4 & & Leu & Cascade & 6 & & 100 \\
\hline 5 & & Ala & One-pot & $6^{\text {c }}$ & & 61 \\
6 & & Leu & One-pot & 6 & & 100 \\
7 & \multirow{2}{*}{ Ethyl pyruvate } & Ala & Cascade & 6 & Ethyl 2-hydroxypropanoate & 54 \\
8 & & Leu & Cascade & 6 & & 100 \\
9 & & Leu & Cascade & $6^{\text {c }}$ & & 12 \\
\hline
\end{tabular}

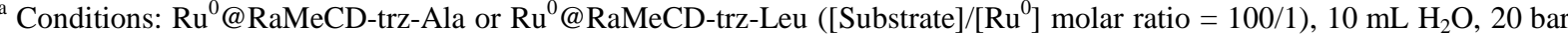

$\mathrm{H}_{2}$, rt. ${ }^{\mathrm{b}}$ Determined by GC analysis. ${ }^{\mathrm{c}} 100 \%$ yield after $18 \mathrm{~h}$ of reaction. ${ }^{\mathrm{d}} 10 \mathrm{eq}$ of RaMeCD-trz-Leu were used.

First, whatever the chiral ligand (RaMeCD-trz-Ala or RaMeCD-trz-Leu) and the preparation methods (one-pot or cascade), the reduction of methyl 2-acetamidoacrylate occurred exclusively on the activated $\mathrm{C}=\mathrm{C}$ double bond with complete conversion in $6 \mathrm{~h}$ (Table 2, Entries 1-4). However, the carbonyl group of ethyl pyruvate was selectively and totally reduced into the corresponding alcohol only with $\mathrm{Ru}^{0} @ \mathrm{RaMeCD}$-trz-Leu (Table 2, Entries 6 and 8), while RaMeCD-trz-Ala-capped $\mathrm{Ru}^{0}$ NPs synthesized by both methods displayed lower reactivity towards this compound (61\% and 54\%, respectively) (Table 2, Entries 5 and 7 ). In all cases, no significant enantiomeric excess was recorded $(<5 \%)$. To improve the enantiodiscrimation during the catalytic process, higher amounts of CDs grafted with chiral amino acids (up to 10 eq.) were introduced, but unfortunately with no enhancement of the asymmetric induction and a dramatic decrease in the initial hydrogenation rate of ethyl pyruvate (12\% after 6) (Table 2, Entry 9, footnote d). Extra amount of added RaMeCD-trz-Leu probably hampered the substrate's approach during the catalytic process, thus lowering the reaction rate. Finally, the complete conversion was achieved in $18 \mathrm{~h}$ of reaction time (Table 2, Entries 5 and 9, footnote c). In a second set of experiments, the influence of the nanocatalyst on the chemoselectivity (carbonyl group vs. aromatic ring) was studied, using acetophenone as substrate. Under the standard reduction conditions, only $\mathrm{Ru}^{0} @ \mathrm{RaMeCD}$-trz-Ala NPs prepared by cascade method led to the quantitative formation of the totally hydrogenated product (1cyclohexylethanol) in $8 \mathrm{~h}$ (Table 3, Entry 3). Other nanocatalysts gave a mixture of 1-cyclohexylethanol and 1phenylethanol as the intermediate obtained from the reduction of the carbonyl group (Table 2, Entries 1, 2 and 4). No 1-cyclohexylethanone intermediate, produced from the reduction of the aromatic ring, was detected, suggesting that the carbonyl group is easily reducible, compared to the aromatic ring. Besides, for both methodologies, Ru ${ }^{0} @$ RaMeCD-trz-Ala nanocatalysts were found slightly more active than RaMeCD-trz-Leucapped $\mathrm{Ru}^{0}$ NPs (Table 3, Entries 1 and 3 vs. 2 and 4). Furthermore, the nanospecies synthesized by the cascade method (Table 3, Entries 3 and 4) also revealed faster kinetics than those formed by the one-pot pathway (Table 3 , Entries 1 and 2).

In a third set experiments, considering the original efficiency of nanoparticles-based catalysts towards the reduction of aromatic rings, the challenging stereoselective hydrogenation of $m$-methylanisole was investigated. The different reactivity of the NPs prepared by both approaches was clearly confirmed. Effectively, the conversion of this disubstituted arene was approximately two times greater in case of NPs prepared by cascade method than those obtained from one-pot system (Table 3, Entries 7 and 8 vs. 5 and 6), probably owing to the NPs sizes. Here, the nature of the ligands provided a comparable effect on the reactivity and the selectivity of the $m$-methylanisole hydrogenation. In all cases the thermodynamically less stable cis compound was the major product providing a diastereoisomeric excess (de) of 50\% (Table 3, Entries 5-8). This selectivity has usually been observed with heterogeneous catalytic systems,[62] and is explained by $\pi$-interactions between the substrate and the catalyst's surface during the process, favouring the addition of hydrogen to only one "face" of the arene.[19,63] For reactivity and selectivity comparisons, 100\% of 1-methoxy-3-methyl-cyclohexane were obtained in higher de values (70-100\% in cis-isomer) with water-soluble Ru ${ }^{0} @$ RaMeCDs NPs [46]because of the less steric hindrance of non-grafted CDs. Increase of the reaction time until $18 \mathrm{~h}$ could simultaneously improve the conversion (up to $100 \%$ ) and the diastereoisomeric selectivity (up to $70 \%$ ) of the $m$-methylanisole's reduction (Table 3, Entry 5, footnote c). However, addition of five additional equivalents of ligands (Table 3, Entry 9, footnote d) affected neither the rate nor the selectivity of hydrogenation reaction. Finally, these adjusted 
conditions did not afford a better value of $e e(<5 \%)$. As observed by DOSY NMR, the high mobility of the CDs at the particles' surface probably limits the chiral induction.

Table 3. Hydrogenation of acetophenone and $m$-methylanisole using $\mathbf{R u}^{0} @$ RaMeCD-trz-Ala and Ru@ RaMeCD-trz-Leu ${ }^{\mathrm{a}}$

\begin{tabular}{|c|c|c|c|c|c|c|}
\hline Entry & Substrate & $\begin{array}{l}\text { Chiral } \\
\text { moiety }\end{array}$ & Method & t (h) & Products & $\begin{array}{l}\text { Yields } \\
(\%)^{\mathrm{b}}\end{array}$ \\
\hline 1 & \multirow{4}{*}{ Acetophenone } & Ala & One-pot & 8 & $\begin{array}{c}\text { 1-Phenylethanol / 1-Cyclohexylethanol } \\
(2 / 98)\end{array}$ & 94 \\
\hline 2 & & Leu & One-pot & 8 & 1-Phenylethanol / 1-Cyclohexylethanol & 87 \\
\hline 3 & & Ala & Cascade & 8 & $\begin{array}{c}\text { 1-Phenylethanol / 1-Cyclohexylethanol } \\
(0 / 100)\end{array}$ & 100 \\
\hline 4 & & Leu & Cascade & 8 & $\begin{array}{l}\text { 1-Phenylethanol / 1-Cyclohexylethanol } \\
\text { (16/84) }\end{array}$ & 92 \\
\hline 5 & \multirow{5}{*}{$m$-Methylanisole } & Ala & One-pot & $6^{c}$ & $\begin{array}{l}\text { 1-Methoxy-3-methylcyclohexane } \\
\text { (cis/trans:75/25) }\end{array}$ & 22 \\
\hline 6 & & Leu & One-pot & 6 & $\begin{array}{c}\text { 1-Methoxy-3-methylcyclohexane } \\
\text { (cis/trans:74/26) }\end{array}$ & 21 \\
\hline 7 & & Ala & Cascade & 6 & $\begin{array}{c}\text { 1-Methoxy-3-methylcyclohexane } \\
\text { (cis/trans:75/25) }\end{array}$ & 42 \\
\hline 8 & & Leu & Cascade & 6 & $\begin{array}{c}\text { 1-Methoxy-3-methylcyclohexane } \\
\text { (cis/trans: 76/24) }\end{array}$ & 47 \\
\hline 9 & & $\mathrm{Leu}^{\mathrm{d}}$ & Cascade & 6 & $\begin{array}{l}\text { 1-Methoxy-3-methylcyclohexane } \\
\text { (cis/trans:76/24) }\end{array}$ & 41 \\
\hline
\end{tabular}

\subsection{Catalytic lifetime of ruthenium(0) nanoparticles}

The catalytic lifetime of $\mathrm{Ru}^{0}$ NPs capped by chirally modified CDs was checked in the hydrogenation of ethyl pyruvate (20 bar $\mathrm{H}_{2}$ at $\mathrm{rt}$ ) to justify their stability (Scheme 2).

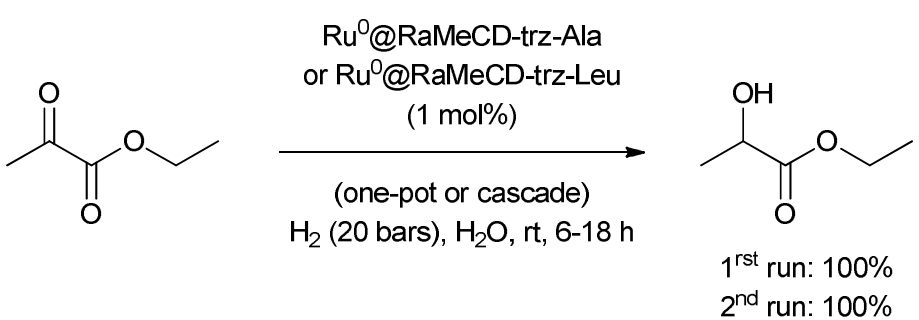

Scheme 2. Catalytic lifetime study of $\mathrm{Ru}^{0} @$ Chiral CDs nanoparticles in the hydrogenation of ethyl pyruvate

After a first run, the aqueous phase containing the nanocatalysts was separated from the hydrogenated product by extraction with ethyl acetate (EtOAc) and then reused in a second run after addition of a new quantity of substrate. All catalytic systems kept both their reactivity and stability since total conversion was achieved and no agglomerates were visually observed during the recycling tests. Consequently, as well as methylated CDs, [46] the RaMeCDs grafted with optically active moieties (Ala or Leu) proved to be efficient supramolecular edifices in the nanoparticle environment to maintain the colloidal solutions within the aqueous phase during the catalytic process in the studied conditions.

\section{Conclusions}

In summary, ruthenium nanoparticles stabilized by 5 equivalents of randomly methylated $\beta$-cyclodextrins grafted with optically active skeletons (L-alanine or L-leucine) were easily and reproducibly prepared by two pertinent methods. Among both approaches, the cascade method offers more flexibility in adjusting the CDs quantities. The nanospecies have been compared in terms of structure, stability and catalytic performances. TEM analyses showed very small $(<1.0 \mathrm{~nm})$ and well-dispersed NPs and DOSY NMR experiments revealed the presence of mobile CD edifices around the particle surface. These observations confirmed an efficient dispersing role of the 
$\mathrm{CDs}$ to prevent NPs from aggregate formation in water. The obtained $\mathrm{Ru}^{0} \mathrm{NPs}$ revealed efficient catalytic activities and selectivities in the biphasic hydrogenation of various prochiral substrates at room temperature under 20 bar $\mathrm{H}_{2}$. Generally, $\mathrm{Ru}$ nanocatalysts containing L-leucine moiety were more active than NPs capped by RaMeCD-trz-Ala and those prepared by the cascade method seem to be more efficient than those synthesized from one-pot method. Finally, the stability of the $\mathrm{Ru}^{0} \mathrm{NPs}$ was also investigated through recycling tests of ethyl pyruvate hydrogenation. Regarding the results, methylated cyclodextrins are relevant candidates for supramolecular catalysis in terms of selectivity. The functionalization of their secondary face by chiral synthons could modify the interactions with the particle's surface as well as with the substrate, and thus may be promising in terms of the (expected) enantiodiscrimination.

\section{Acknowledgements}

The authors are grateful to CNRS and the Agence Nationale de la Recherche (ANR-09-BLAN-0194) for the financial support of the SUPRANANO program. We are also indebted to Patricia Beaunier from Université Pierre et Marie Curie for obtaining the TEM images.

\section{References}

[1] J.K. Whitesell, Chem. Rev. 92 (1992) 953-964.

[2] R.-L. Gu, C. J. Sih, Tetrahedron Lett. 31 (1990) 3287-3290.

[3] M. Besson, B. Blanc, M. Champelet, P. Gallezot, K. Nasar, C. Pinel, J. Catal. 170 (1997) 254264.

[4] M. Besson, S. Neto, C. Pinel, Chem. Commun. (1998) 1431-1432.

[5] M. Besson, P. Gallezot, S. Neto, C. Pinel, Tetrahedron: Asymmetry. 11 (2000) 1809-1818.

[6] P. Kukula, R. Prins, Top. Catal. 25 (2003) 29-42.

[7] V. Polshettiwar, T. Asefa (Eds.), Nanocatalysis: Synthesis and Applications, WILEY-VCH, Boschstrasse 12, D-69469 Weinheim, 2013.

[8] Y. Yuan, N. Yan, P.J. Dyson, ACS Catalysis. 2 (2012) 1057-1069.

[9] A. Roucoux, A. Nowicki, K. Philippot, in: D. Astruc (Ed.), Nanoparticles and Catalysis, Wiley-VCH Verlag GmbH \& Co. KGaA, 2008, pp. 349-388.

[10] A. Gual, C. Godard, S. Castillon, C. Claver, Dalton Trans. 39 (2010) 11499-11512.

[11] J.P. Wilcoxon, B.L. Abrams, Chem. Soc. Rev. 35 (2006) 1162-1194.

[12] R. Narayanan, M. El-Sayed, Top. Catal. 47 (2008) 15-21.

[13] D. Astruc, Nanoparticles and Catalysis, Wiley-VCH Verlag GmbH \& Co. KGaA, 2008, pp. 148.

[14] B. Chaudret, K. Philippot, in: R. H. Crabtree, D.M.P. Mingos (Eds.), Comprehensive Organometallic Chemistry III, Elsevier, Oxford, 2007, pp. 71-99.

[15] L.D. Pachón, G. Rothenberg, Appl. Organomet. Chem. 22 (2008) 288-299.

[16] A. Roucoux, J. Schulz, H. Patin, Chem. Rev. 102 (2002) 3757-3778.

[17] V. Mévellec, C. Mattioda, J. Schulz, J.-P. Rolland, A. Roucoux, J. Catal. 225 (2004) 1-6.

[18] S. Roy, M.A. Pericas, Org. Biomol. Chem. 7 (2009) 2669-2677.

[19] K. Nasar, F. Fache, M. Lemaire, J.-C. Béziat, M. Besson, P. Gallezot, J. Mol. Catal. 87 (1994) 107-115.

[20] S. Jansat, D. Picurelli, K. Pelzer, K. Philippot, M. Gomez, G. Muller, P. Lecante, B. Chaudret, New J. Chem. 30 (2006) 115-122.

[21] A. Gual, M.R. Axet, K. Philippot, B. Chaudret, A. Denicourt-Nowicki, A. Roucoux, S. Castillon, C. Claver, Chem. Commun. (2008) 2759-2761.

[22] A. Gual, C. Godard, K. Philippot, B. Chaudret, A. Denicourt-Nowicki, A. Roucoux, S. Castillón, C. Claver, ChemSusChem. 2 (2009) 769-779.

[23] P.T. Anastas, J.C. Warner (Eds.), Green Chemistry: Theory and Practice, Oxford University Press, New York, 1998.

[24] T. Mallat, E. Orglmeister, A. Baiker, Chem. Rev. 107 (2007) 4863-4890.

[25] F.-X. Felpin, E. Fouquet, ChemSusChem. 1 (2008) 718-724.

[26] K.D.M. Harris, S.J.M. Thomas, ChemCatChem. 1 (2009) 223-231.

[27] V. Polshettiwar, R.S. Varma, Green Chem. 12 (2010) 743-754. 
[28] A. Denicourt-Nowicki, A. Roucoux, in: P. Serp, K. Philippot (Eds.), Nanomaterials in Catalysis, Wiley-VCH, Weinheim, 2013, pp. 55-96.

[29] T. Dwars, E. Paetzold, G. Oehme, Angew. Chem. 117 (2005) 7338-7364.

[30] T. Dwars, E. Paetzold, G. Oehme, Angew. Chem., Int. Ed. 44 (2005) 7174-7199.

[31] E. Paetzold, G. Oehme, J. Mol. Catal. A: Chem. 152 (2000) 69-76.

[32] A. Roucoux, J. Schulz, H. Patin, Adv. Synth. Catal. 345 (2003) 222-229.

[33] C. Hubert, A. Denicourt-Nowicki, J.P. Guégan, A. Roucoux, Dalton Trans. 36 (2009) 73567358.

[34] E. Guyonnet Bilé, R. Sassine, A. Denicourt-Nowicki, F. Launay, A. Roucoux, Dalton Trans. 40 (2011) 6524-6531.

[35] E. Guyonnet Bilé, A. Denicourt-Nowicki, R. Sassine, P. Beaunier, F. Launay, A. Roucoux, ChemSusChem. 3 (2010) 1276-1279.

[36] E. Guyonnet Bilé, E. Cortelazzo-Polisini, A. Denicourt-Nowicki, R. Sassine, F. Launay, A. Roucoux, ChemSusChem. 5 (2012) 91-101.

[37] F. Hapiot, J. Lyskawa, H. Bricout, S. Tilloy, E. Monflier, Adv. Synth. Catal. 346 (2004) 8389.

[38] M. Baur, M. Frank, J. Schatz, F. Schildbach, Tetrahedron. 57 (2001) 6985-6991.

[39] S.C. Mhadgut, K. Palaniappan, M. Thimmaiah, S.A. Hackney, B. Torok, J. Liu, Chem. Commun. (2005) 3207-3209.

[40] E. Monflier, S. Tilloy, Y. Castanet, A. Mortreux, Tetrahedron Lett. 39 (1998) 2959-2960.

[41] A.R. Khan, P. Forgo, K.J. Stine, V.T. D'Souza, Chem. Rev. (Washington, DC, U. S.). 98 (1998) 1977-1996.

[42] S. Tilloy, H. Bricout, E. Monflier, Green Chem. 4 (2002) 188-193.

[43] T. Mathivet, C. Méliet, Y. Castanet, A. Mortreux, L. Caron, S. Tilloy, E. Monflier, J. Mol. Catal. A: Chem. 176 (2001) 105-116.

[44] A. Denicourt-Nowicki, A. Roucoux, Curr. Org. Chem. 14 (2010) 1266-1283.

[45] A. Denicourt-Nowicki, A. Ponchel, E. Monflier, A. Roucoux, Dalton Trans. (2007) 57145719.

[46] N.T.T. Chau, S. Handjani, J.-P. Guegan, M. Guerrero, E. Monflier, K. Philippot, A. DenicourtNowicki, A. Roucoux, ChemCatChem. 5 (2013) 1497-1503.

[47] A. Nowicki, Y. Zhang, B. Leger, J.-P. Rolland, H. Bricout, E. Monflier, A. Roucoux, Chem. Commun. (2006) 296-298.

[48] J. Szejtli, T. Osa, in: J. Szejtli, T. Osa (Eds.), Comprehensive Supramolecular Chemistry, Pergamon, Oxford, 1996, pp. 185-204.

[49] D.N. Tran, C. Blaszkiewicz, S. Menuel, A. Roucoux, K. Philippot, F. Hapiot, E. Monflier, Carbohydr. Res. 346 (2011) 210-218.

[50] H.-Y. Kim, J. Sohn, G.T. Wijewickrama, P. Edirisinghe, T. Gherezghiher, M. Hemachandra, P.-Y. Lu, R.E. Chandrasena, M.E. Molloy, D.A. Tonetti, G.R.J. Thatcher, Bioorg. Med. Chem. 18 (2010) 809-821.

[51] D. Astruc, C. Ornelas, A.K. Diallo, J. Ruiz, Molecules. 15 (2010) 4947-4960.

[52] E. Boisselier, A.K. Diallo, L. Salmon, C. Ornelas, J. Ruiz, D. Astruc, J. Am. Chem. Soc. 132 (2010) 2729-2742.

[53] J. Yang, J.Y. Lee, T.C. Deivaraj, H.-P. Too, J. Colloid Interface Sci. 271 (2004) 308-312.

[54] Nan Yao, Z.L. Wang, Handbook of Microscopy for Nanotechnology 1st ed., Springer, New York, 2005.

[55] S. Mandal, P. Selvakannan, S. Phadtare, R. Pasricha, M. Sastry, Proc.- Indian Acad. Sci., Chem. Sci. 114 (2002) 513-520.

[56] O. Horovitz, A. Mocanu, G. Tomoaia, L. Bobos, D. Dubert, I. Daian, T. Yusanis, M. Tomoaia-Cotisel, Stud. Univ. Babes-Bolyai, Chem. 52 (2007) 97-108.

[57] K.F. Morris, C.S. Johnson, J. Am. Chem. Soc. 114 (1992) 3139-3141.

[58] P.-J. Debouttière, Y. Coppel, A. Denicourt-Nowicki, A. Roucoux, B. Chaudret, K. Philippot, Eur. J. Inorg. Chem. 2012 (2012) 1229-1236.

[59] A. Macchioni, G. Ciancaleoni, C. Zuccaccia, D. Zuccaccia, Chem. Soc. Rev. 37 (2008) 479489.

[60] A. Nowicki, V. Le Boulaire, A. Roucoux, Adv. Synth. Catal. 349 (2007) 2326-2330. 
[61] S. Gatard, L. Liang, L. Salmon, J. Ruiz, D. Astruc, S. Bouquillon, Tetrahedron Lett. 52 (2011) 1842-1846.

[62] H. Nagahara, M. Ono, M. Konishi, Y. Fukuoka, Appl. Surf. Sci. 121-122 (1997) 448-451.

[63] T.Q. Hu, C.-L. Lee, B.R. James, S.J. Rettig, Can. J. Chem. 75 (1997) 1234-1239. 